\title{
Studies MicroRNA 208 as a Novel Cardiac Marker in Acute Coronary Syndrome in Egyptian Patients
}

\author{
MOHAMED Y. NASR, Ph.D.*; SALWA E. MOHAMED, Ph.D.*; ABLA A. MOHAMED, B.Sc.** and \\ SABAH F. EL-ABED, Ph.D.*** \\ The Department of Biochemistry of Molecular Biology, Genetic Engineering Biotechnology Researches Institute, \\ Sadat City University*, The Department of Chemistry Laboratory, National Heart Institute, Imbaba, Giza** and \\ The Department of Molecular Pathology Molecular Biology, Genetic Engineering Biotechnology Researches Institute, \\ Sadat City University***
}

\begin{abstract}
Background: Acute coronary syndrome ACS patients presented to Emergency Department ED require rapid differential diagnosis. Although troponin is the gold marker for ACS, there still undiagnosed patients. MicroRNAs circulate in human plasma and affected by varying cardiac pathologies. miRNA-208 was found to be elevated with ACS specially AMI.
\end{abstract}

Aim of Study: The aim of this study was to investigate cTnI levels, correlated to miRNA-208 levels in ACS patients to evaluate rapid, accurate and final diagnosis in ED.

Subjects and Methods: One hundred consecutive patients with ACS presenting to the Emergency Department of the National Heart Institute, Giza (Egypt) between March and June 2018, were recruited for the study, stratified into four groups according to the final diagnosis as AMI (including twenty five patients) and unstable angina UA (including twenty three patients), other cardiac patients (eighteen patients) and non cardiac (fourteen patients) twenty control subjects. Were included their cardiac markers and miRNA-208 levels were assayed and compared to the control healthy group on admission.

Results: Results revealed significant difference between cardiac levels on admission compared to that obtained for miRNA-208. Only miRNA-208 levels were diagnosed on admission compared to that of cTnI. MiRNA-208 was found to be increased up to 38.6 folds without differential cut off.

Conclusion: Early measurement of both troponin I and miRNA-208 may revolutionize the diagnostic accuracy and therapeutic decision-making in patients with symptoms suggestive of ACS; differentiate between UA or AMI patients on admission. Cardiac troponin $1 \mathrm{cTnI}$ alone require more time to be controlled as diagnostic while high sensitive cTn may lead to false positive results. MiRNA-208 can be used as a novel marker for early diagnosis of ACS although RT-PCR still time consuming, requires time improved techniques.

Correspondence to: Dr. Mohamed Y. Nasr, The Department of Biochemistry of Molecular Biology, Genetic Engineering Biotechnology Researches Institute, Sadat City University
Key Words: Acute coronary syndrome - Novel cardiac marker - MicroRNA 208.

\section{Introduction}

RAPID and accurate diagnosis is critical for acute coronary syndrome patients for medical control and catheterization intervention. Recently, rapid rule-in or rule-out are now available for patients with chest pain in the Emergency Department (ED), and enable either rapid treatment or discharge. 12lead electrocardadiogram ECG and cardiac troponin (cTn) I or T constitutes the main diagnostic criteria of patients with Acute Coronary Syndrome (ACS). Nevertheless, other cardiac diseases such as myocarditis, Tako-tsubo cardiomyopathy or shock can significantly increase troponin levels [1]

Cardiac troponin was first described as a cardiac disease marker in 1963 [2]. National Academy of Clinical Biochemistry (NACB) in 1999 considered plasma cardiac troponin concentrations as a novel marker for assessment of suspected Acute Coronary Syndrome (ACS) [3]. Since 2000, cardiac troponin has been announced as the golden biomarker of Myocardial Infarction (MI) [4].

Cardiac troponin concentrations are often increased in some non-ACS conditions including myocarditis and cardiomyopathy, indicating prognostic information leading to mortality or worsening heart failure. Studies investigating the prognostic benefit of cardiac troponin in non-ACS patients' treatments are lacking and not well defined. Hence, cTns have some diagnostic pitfalls and there is a need for more sensitive and specific cardiac biomarker [5] 
Genetic studies have suggested about 60 genetic loci for coronary artery diseases risk. Gene sequencing and functional studies have facilitated a better understanding of coronary artery (disease) CAD risk factors, elucidated underlying biology and informed the development of new therapeutics. Such genetic studies could enable valuable medicine approaches by classifying patients to subgroups whom at increased risk of atherosclerosis, coronary artery disease and Acute Coronary Syndromes (ACS) or those with an increased pathophysiology, require therapeutic or preventive medication [6] .

MicroRNAs (miRNAs) are minute non-coding RNAs with 20-25 nucleotide. They can bind messenger RNAs (mRNAs), cause their degradation, leading to translational termination and consecutively regulate gene expression. Hence, they are regulators of cellular pathways in proliferation and differentiation [7]. miRNAs expression patterns are specific for different organs and cell types and can be secreted into different types of body fluids such as blood and urine, which allows them to transmit their signal to different cells and tissues. This allows them to be circulating biomarkers for a variety of diseases specific for every organ or tissue [8]. The number of miRNA gene has grown to be more than 3000, and about 1000 mature miRNAs have been identified in the human genome [9]

MiRNA-208 family is known to be heart specific, consist of three miRNAs, miRNA-208a, miRNA-208b and miRNA-499. Quantitative realtime Polymerase Chain Reaction (qPCR) analysis for miRNA-208 family in various organs, including the heart, brain, kidney, lung, liver, and skeletal muscles, revealed that miR-208a is exclusively expressed in the heart, whereas miR-208b and miR-499 are expressed in embryonic heart and skeletal muscles [10]. MiR-208a function is the cardiac development of heavy myosin chain synthesis. Some studies also suggest that miR-208a can serve as heart failure prevention [11]

The aims of this study research were the assessment of expression level of miRNA-208a in plasma in patients with STEMI, stable CAD and healthy individuals; evaluation of correlation between plasma miRNAs and post infarction heart failure prediction and also correlation to troponin release in patients with ACS.

\section{Material and Methods}

Patients were randomly selected from acute myocardial infraction AMI, unstable angina-ACS groups-admitted to the emergency room or Intensive Coronary Care Unit, National Heart Institute (NHI), Giza, Egypt. Between March and June 2018 control group was matched by age and gender to ACS control group-participants didn't suffer from arterial hypertension nor stable angina pectoris and their echocardiographic exam was normal (without signs of the left ventricle wall hypertrophy or systolic or diastolic dysfunction). Prior the recruitment of participants, this study was approved by the Ethics Committee of Clinical Center of the NHI.

Blood samples for B-type natriuretic peptide BNP analysis in ACS groups were taken within first hours from the beginning of the symptoms. BNP was determinated with AxSYM assay (Abbott Laboratory) from venous blood collected in EDTA plastic tubes (Ethylenediaminetetraacetic acid). Left Ventricle Ejection Fraction (LVEF) was determined by transthoracic echocardiographic examination by calculation method of Teicholtz and Simpson under supervision of the cardiologist consultants of NHI.

Quantitative Reverse Transcription-Polymerase Chain Reaction (qRT-PCR).

Real-time PCR assays were performed using the ExiLENT SYBR ${ }^{\circledR}$ Green Master Mix Kit (Exiqon). LNA primers were purchased from Exiqon. cDNA was diluted $10 \mathrm{x}$ and added to the PCR reactions according to the manufacturer's instructions. The real-time PCR program included the following steps: An initial denaturation step at $95^{\circ} \mathrm{C}$ for $10 \mathrm{~min}$ and 50 cycles of amplification that con-sisted of a denaturation step $\left(10 \mathrm{~s}\right.$ at $\left.95^{\circ} \mathrm{C}\right)$ and an annealing step $\left(60\right.$ s at $\left.60^{\circ} \mathrm{C}\right)$.

\section{Primer design:}

For quantification of miRNA208 cDNA pair of primers was used according to Brockhaus and Brune (1999) for the amplification of cDNA. MiScript primer sequence used in this study were synthesized in the QIAGEN, Sample \& Assay Technologies, Germany. Sequence of the miRNA 208 is (AUAACGACAAAAAGCUUGU). The number of bases of miScript primer are 19 mer.

\section{Statistical analysis:}

Data are expressed as a mean \pm SD or median and interval. For parametric variables not belonging to the same population student $t$-test was used while for multiple groups we used ANOVA test. Pearson' s correlation test was used to assess association between measured parameters. $p$-values less than 0.05 was considered as statistically sig- 
nificant. For the statistical evaluation of data computer program SPSS versio was used.

\section{Results}

1 - Cardiac markers data for investigated subjects:

Cardiac markers data were shown in Table (1). using ANOVA tested there were significant for all cardiac markers due to high levels obtained in AMI group.

CK activities for control group were found to be $60.9 \pm 14.03 \mathrm{U} / \mathrm{L}$. All other groups' ck activities were significantly high including subjects who suffer chest pain rather than cardiac. Although such groups has normal CK activity levels (less than upper limit of 190U/L), but they are still at least double fold of control group (188.57 \pm 41.08 for UA, 398.00 \pm 41.08 for MI, $125.78 \pm 41.28$ for cardiac non ACS \& $125.57 \pm 42.02 \mathrm{U} / \mathrm{L}$ respectively).

CK-MB activities were $5.25 \pm 1.02$ in control group, $7.57 \pm 3.76$ for UA, $13.00 \pm 5.192$ for cardiac non ACS $16.43 \pm 5.85 \mathrm{U} / \mathrm{L}$ for non cardiac group. Only MI group has got highly elevated levels of CK-MB (62.76 $\pm 15.23 \mathrm{U} / \mathrm{L})$ which causes the significant difference in ANOVA for CK-MB.

LDH activities were found to be elevated only in the MI group $(572.80 \pm 114.98 \mathrm{U} / \mathrm{L})$ while be kept within the normal range $(<460 \mathrm{U} / \mathrm{L})$ in all other

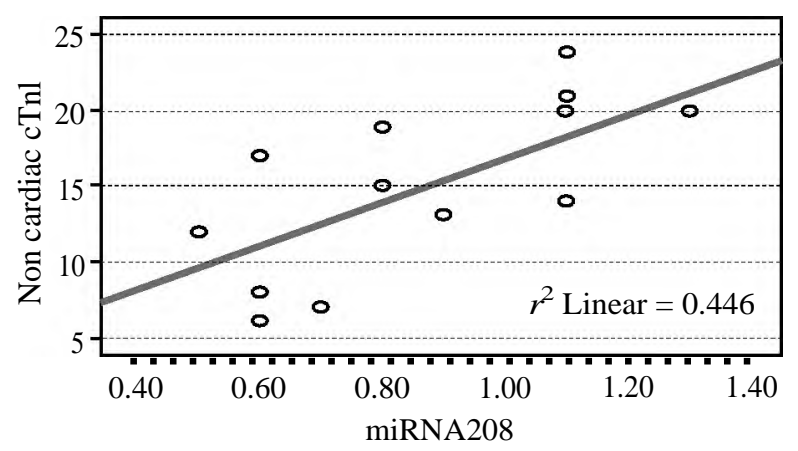

Fig. (1): Correlation between cTnI and miRNA208 in group non cardiac patients

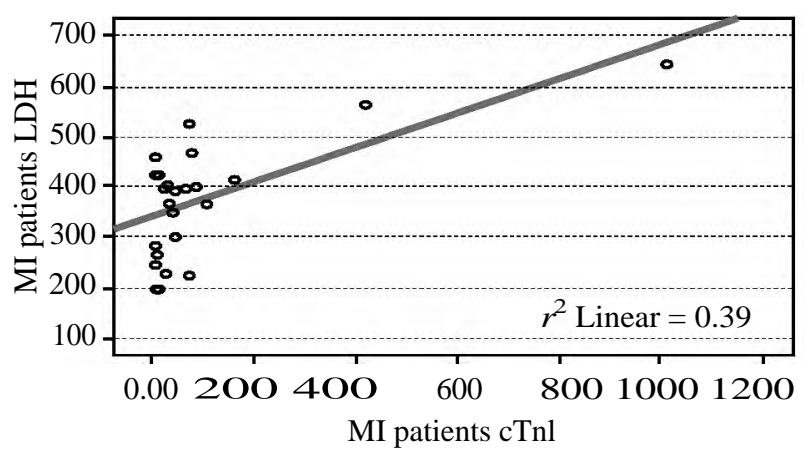

Fig. (3): Correlation between LDH and cTnl in group MI patients groups including UA group (326.61 \pm 84.93$)$, cardiac non ACS group (331.89 \pm 76.58$)$ and non cardiac group (332.86 \pm 52.11 ) compared to control group $(225.35 \pm 47.08)$.

Concerning the golden marker of cardiac necrosis, cardiac troponin I (cTnI), all results for investigated groups were lowers than cut off level $(<20$ $\mathrm{pg} / \mathrm{ml})$. Except MI group showed very high levels (63.50 \pm 208.26$)$ confirming cardiac necrosis due to MI. It is noticed that SD was very high and this is due to wide variations of observed cTnI levels in this group. cTnI levels was $9 \pm 3.45 \mathrm{pg} / \mathrm{ml}$ in control subjects but mild increased in the other three groups rather than MI group to be found $11.13 \pm 4.24$ in UA, $13.67 \pm 5.49$ in the other cardiac group \& $15.00 \pm 5.52$ in non cardiac group.

The most important finding is miRNA-208 levels since they are elevated to more than 60 fold in MI patients (58.58 \pm 17.77$)$ while there is no elevation or even non detected in the all other groups with mean of 0.8 fold in them.

\section{2- MiR208 level:}

Data in Table (2) shows miRNA-208 levels since they were elevated to more than 60 fold in MI patients $(58.58 \pm 17.77)$ while there is no elevation or even non detected in the all other groups with mean of 0.8 fold in them and SD 0.25 .

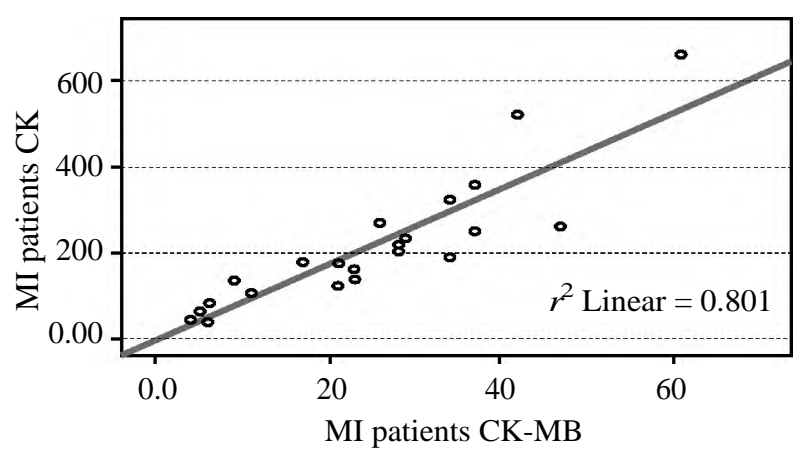

Fig. (2): Correlation between CK-total and CK-MB in group MI patients

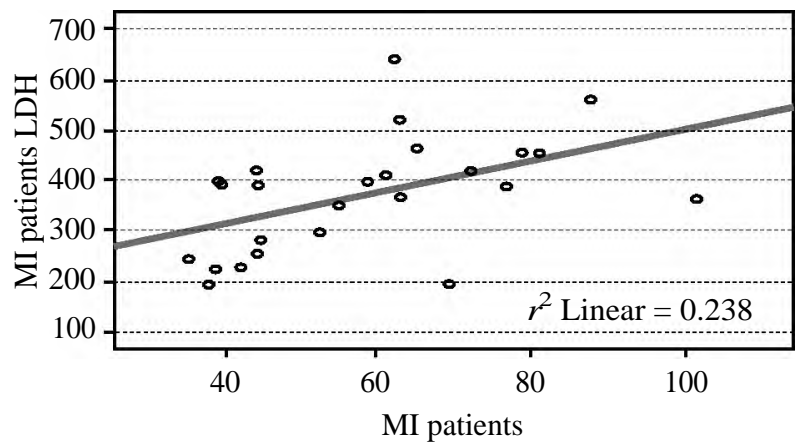

Fig. (4): Correlation between LDH and miRNA208 in group MI patients. 
Table (1): Cardiac markers in control subjects and other studied groups.

\begin{tabular}{|c|c|c|c|c|c|c|c|c|c|c|c|}
\hline \multirow{2}{*}{$\begin{array}{l}\text { Analytical } \\
\text { parameters }\end{array}$} & \multicolumn{2}{|c|}{ Group I $(n=20)$} & \multicolumn{2}{|c|}{ Group II (n=23) } & \multicolumn{2}{|c|}{ Group III (n=25) } & \multicolumn{2}{|c|}{ Group IV $(n=18)$} & \multicolumn{2}{|c|}{ Group V (n=14) } & \multirow{2}{*}{$p$-value } \\
\hline & Mean & S.D & Mean & S.D & Mean & S.D & Mean & S.D & Mean & S.D & \\
\hline CK U/L & 60.90 & 14.03 & 188.57 & 41.08 & 398.00 & 148.02 & 125.78 & 41.28 & 125.57 & 42.02 & $<0.05$ \\
\hline CK-MB U/L & 5.25 & 1.02 & 7.57 & 3.76 & 62.76 & 15.23 & 13.00 & 5.92 & 16.43 & 5.85 & \\
\hline LDH U/L & 225.35 & 47.08 & 326.61 & 84.93 & 572.80 & 114.98 & 331.89 & 76.58 & 332.86 & 52.11 & \\
\hline cTnI PG/ML & 9.00 & 3.45 & 11.13 & 4.24 & 63.50 & 208.26 & 13.67 & 5.49 & 15.00 & 5.52 & \\
\hline $\begin{array}{l}\text { Group II : UA } \\
\text { Group III : MI }\end{array}$ & $\begin{array}{l}\text { tients. } \\
\text { ients. }\end{array}$ & & $\begin{array}{l}\mathrm{Gr} \\
p\end{array}$ & Is cons & d signific & t when & & & & & \\
\hline
\end{tabular}

Table (2): MiRNA-208 levels in investigated subjects (fold increase).

\begin{tabular}{|c|c|c|c|c|c|c|c|c|c|c|c|}
\hline \multirow{2}{*}{$\begin{array}{l}\text { Analytical } \\
\text { parameters }\end{array}$} & \multicolumn{2}{|c|}{ Group I $(n=20)$} & \multicolumn{2}{|c|}{ Group II $(n=23)$} & \multicolumn{2}{|c|}{ Group III $(n=25)$} & \multicolumn{2}{|c|}{ Group IV $(n=18)$} & \multicolumn{2}{|c|}{ Group V $(n=14)$} & \multirow{2}{*}{$p$-value } \\
\hline & Mean & S.D & Mean & S.D & Mean & S.D & Mean & S.D & Mean & S.D & \\
\hline miR208 & 0.81 & 0.41 & 4.17 & 1.70 & 58.58 & 17.77 & 0.81 & 0.35 & 0.88 & 0.25 & $<0.05$ \\
\hline $\begin{array}{l}\text { Group I : C } \\
\text { Group II : U } \\
\text { Group III : M }\end{array}$ & $\begin{array}{l}\text { atients. } \\
\text { atients. }\end{array}$ & & $\begin{array}{l}\text { Group } \\
\text { Group } \\
p\end{array}$ & $\begin{array}{l}\text { Non ce } \\
\text { Is con }\end{array}$ & ed signi & twher & & & & & \\
\hline
\end{tabular}

\section{Discussion}

As proposed in this study miRNA-208 levels were highly, specifically elevated in all patients on admission to the Emergency Department by about 58.5 fold. MiRNA-208 is widely accepted as myocardial specific type of miRNAs [12]. Wang et al., [13] evaluated its potential role as myocardial biomarker among many myocardiac specific and musclular tissue-specific microRNAs. They confirmed its myocardial specificity and sensitivity of as MI biomarker with $90.9 \%$ for sensitivity and $100 \%$ for specificity. The most profound character of miRNA-208 as cardiac biomarker is its peak after only 1 hour of MI onset. That is to say miRNA-208 is a valuable biomarker of cardiac ischemia and co-operates with troponins as early markers for rule in or rule out of patients with chest pain [13].

Gidlöf et al., [14] reported that both miRNA208 $\& 499$ had a prognostic value similar to cTns for the prediction of an adverse cardiovascular event within 30 days, but they did not bring additional value in combination with cTn. Also, miRNAs higher levels in AMI patients correlated with left ventricular systolic dysfunction measured by the left ventricular ejection fraction. In 2017, Liu et al., [15] measured circulating plasma miRNA-208 and they found higher levels in a AMI patients compared to unstable angina patients and healthy controls. Moreover, in this study, results showed that miRNA-208 was as sensitive as creatine kinase MB isoform and cTnI for the diagnosis of AMI. They also suggested miRNA-208 as a prognostic biomarker heart failure and other future cardiac events [16].

$\mathrm{Ck}, \mathrm{CK}-\mathrm{MB}$ and $\mathrm{LDH}$ activities were found high correlated to final diagnosis in this study. In 1979, the World Health Organization (WHO) demonstrated CK, CK-MB, LDH, or AST higher activities as markers of AMI. Although their compatible results to the ACS status, there are many considerations affect their results including pre-analytical or analytical variables (e.g., prolonged storage or inadequate preservation, inhibitors or interference from other enzymes or drugs, $\mathrm{pH}$ and ionic concentrations used in the analyses and assay temperature) may influence the CK-MB activity. Moreover, the evidence that the activity of CK-MB can be considerably enhanced in many skeletal muscle disorders and release from the injured muscle cell, lead to pitfalls in the reliability as cardiac biomarkers [17].

cTnI levels were found profound high in the AMI group, but still higher in all other groups compared to control group. Hence there are other causes rather than cardiac necrosis may affect $\mathrm{cTnI}$ elevations. General misunderstand that troponin elevation is secondary to cardiac myocyte injury and necrosis is widely accepted. In fact there are at least six mechanisms to explain the release of troponin into the bloodstream through cardiac muscles including normal cell turnover, regular myocyte necrosis, apoptosis, proteolytic fragmentation, increased cell membrane permeability and membranous blebs. Moreover, ischemic elevation of cTn without cardiac myocyte necrosis remains 
controversial [18]. Some studies demonstrated an association between reversible ischemia (no evidence of MI) and cTn elevation [19]. Increased myocardial strain is also considered to be associated with cTn elevation [20]

There is a risk of misinterpretation of elevated troponin results. Almost 13\% of patients presenting with raised hscTn and chest pain eventually prove not to have ACS. Hs-cTn can be detected in patients with various cardiac and non-coronary cardiovascular co-morbidities. Whether or not cTn is detectable, or even elevated, is therefore dependent on the balance of a host of interdependent factors, including the sensitivity of the test [21].

The evaluation of patients presenting at the Emergency Department (ED) with suspected ACS remains a clinical challenge. The traditional assessment includes clinical risk assessment based on symptoms, Cardiovascular (CV) risk factors with serial electrocardiograms and hsTn measurements, often followed by advanced cardiac testing as inpatients or outpatients [22]. With regards to hsTn, several cohort studies have shown that patients with undetectable plasma hsTn concentrations at presentation are at low risk of MI. However, the optimal approach and threshold of hsTn for the identification of low-risk patients suitable for immediate discharge is still debated.

Shah et al., [23] made a prospective cohort study of 6304 consecutively enrolled patients with suspected ACS presenting to 4 secondary and tertiary care hospitals in Scotland. They measured plasma Tn concentrations at presentation using a hsTnI assay and evaluated the negative predictive value of a range of hsTnI concentrations for the primary outcome of index MI, or subsequent MI or cardiac death at 30 days in derivation and validation cohorts. The median time from arrival in the ED to blood sampling for measurement of hsTn was $54 \mathrm{~min}$. They found that a hsTn concentration of less than $5 \mathrm{ng} / \mathrm{L}$ at presentation met their prespecified criteria for a negative predictive value of at least $99.5 \%$. At this threshold, almost twothirds of patients with suspected ACS could have been discharged with very few cardiac events. Indeed, implementation of this threshold could double the number of patients discharged directly from the ED.

In one study, Pickering et al., [24] tested the 0$1 \mathrm{~h}$ rule out algorithm proposed by the current European Guidelines on 2015 ESC guidelines for the management of ACS in patients presenting without persistent ST-segment elevation, in 2222 patients with serial hsTnT and hsTnI measurements. The $0-1 \mathrm{~h}$ hsTnT algorithm ruled out 1425 patients $(64.1 \%)$ with a sensitivity of $97.1 \%$. The $0-1 \mathrm{~h}$ hsTnI algorithm ruled out 1205 patients (54.2\%) with a sensitivity of $98.8 \%$. They concluded that the sensitivity of the European Society of Cardiology rapid assessment $0-1 \mathrm{~h}$ algorithm to rule-out AMI with high sensitivity troponin may be insufficient for some ED physicians to confidently send patients home.

Thus, the identification of the optimal rule-out hsTn algorithm in patients with suspected ACS admitted to ED remains debated as well as the optimal rule-in algorithm. With regards to new biomarkers in the early diagnosis of ACS, in a proof of concept study Coskunpinar et al., [25] assessed the potential diagnostic role of circulating micro-RNAs in patients with ACS.

Of course, high levels in MI group is due to cardiac necrosis but the elevated activities in the other groups may be of muscular origin due to chest muscle spasm accompany chest pain.

This suggestion may be confirmed by CK-MB sub-fraction activities which are more specific for cardiac since all groups showed non specific difference except for MI group.

\section{Conclusion:}

Cardiac biomarkers for diagnosis of AMI have become more and more sensitive in recent decades. The currently used cTn assays are highly valuable for rule-in and ruleout of AMI. International guidelines have been published for appropriate use of $\mathrm{cTn}$. Acute changes in cTn complement the quantitative information provided by $\mathrm{cTn}$, and help in the differential diagnosis of diseases with chronic, stable troponin elevations vs. diseases with acute troponin elevations and acute cardiac damage. Testing of cTn does not differentiate myocardial infarction in many cases and, hence, integrating the results of miRNA-208 measurements with robust clinical assessment remains the optimal approach. miRNA-208 is very rapid ACS marker increase within one hour after MI and absolute cardiac marker with $100 \%$ specificity. PCR is still needs to be time improved to use miRNA as novel biomarker.

\section{References}

1- GARG P., MORRIS P., FAZLANIE A.L., VIJAYAN S., DANCSO B., DASTIDAR A.G., PLEIN S., MUELLER C. and HAAF P.: Cardiac biomarkers of acute coronary syndrome: From history to high-sensitivity cardiac troponin. Intern. Emerg. Med., 12: 147-55, 2017. 
2- EBASHI S.: Third component participating in the superprecipitation of natural actomyosin. Nature, 200: 1010, 1963.

3- PANTEGHINI M., APPLE F.S., CHRISTENSON R.H., DATI F., MAIR J. and WU A.H.: Use of biochemical markers in acute coronary syndromes. IFCC Scientific Division, Committee on Standardization of Markers of Cardiac Damage. Clin. Chem. Lab. Med., 37: 687-93, 1999.

4- THYGESEN K., ALPERT J.S., JAFFE A.S., SIMOONS M.L. and CHAITMAN B.R., WHITE H.D., et al.: Third universal definition of myocardial infarction. J. Am. Coll. Cardiol., 60: 1581-98, 2012.

5- EGGERS K.M. and LINDAHL B.: Application of cardiac troponin in cardiovascular diseases other than acute coronary syndrome. Clinical Chemistry, 63: 1 223-35, 2017.

6- KHERA A.V. and KATHIRESAN S.: Genetics of coronary artery disease: Discovery, biology and clinical translation. Nature Reviews: Genetics, 1-14, 2017.

7- SCHULTE C., KARAKAS M. and ZELLER T.: MicroRNAs in cardiovascular disease-clinical application. Clin. Chem. Lab. Med., 55 (5): 687-704, 2017.

8- FAN H.M., SUN X.Y., GUO W., ZHONG A.F., NIU W., ZHAO L., et al.: Differential expression of microRNA in peripheral blood mononuclear cells as specific biomarker for major depressive disorder patients. J. Psychiatr. Res., 59: 45-52, 2014.

9- HUANG Y. and LI J.: MicroRNA208 family in cardiovascular diseases: Therapeutic implication and potential biomarker. J. Physiol. Biochem., 71: 479-86, 2015.

10- JI X., TAKAHASHI R., HIURA Y., HIROKAWA G., FUKUSHIMA Y. and IWAI N.: Plasma miR-208 as a biomarker of myocardial injury. Clin. Chem. 55: 19449, 2009.

11-MONTGOMERY R.L., HULLINGER T.G., SEMUS H.M., DICKINSON B.A., SETO A.G., LYNCH J.M., et al.: Therapeutic inhibition of miR-208a improves cardiac function and survival during heart failure. Circulation, 14: 1537-47, 2011.

12- NABIALEK E., WAN'HA W., KULA D., JADCZYK T., KRAJEWSKA M., KOWALOWKA A., DWOROWY S., HRYCEK E., WL UDARCZYK W., PARMA Z., MICHALEWSKA-WLUDARCZYK A., PAWLOWSKI T. OCHALA B., JARZAB B., TENDERA M. and WOJAKOWSKI W.: Circulating microRNAs (miR-423-5p, miR208a and miR-1) in acute myocardial infarction and stable coronary heart disease. Minerva Cardioangiol., 61: 62737, 2013.

13- WANG G.K., ZHU J.Q., ZHANG J.T., LI Q., LI Y, HE J., et al.: Circulating microRNA: A novel potential biomarker for early diagnosis of acute myocardial infarction in humans. Eur. Heart J., 6: 659-66, 2010.
14- GIDLÖF O., SMITH J.G., MIYAZU K., GILJE P., SPENCER A., BLOMQUIST S., et al.: Circulating cardioenriched microRNAs are associated with long-term prognosis following myocardial infarction. BMC Cardiovasc. Disord, 13: 12, 2013.

15- LIU X., YUAN L., CHEN F., ZHANG L., CHEN X., YANG C., et al.: Circulating miR-208b: A potentially sensitive and reliable biomarker for the diagnosis and prognosis of acute myocardial infarction. Clin. Lab., 63: 101-9, 2017.

16- PAIVA S. and AGBULUT O.: MiRroring the Multiple Potentials of MicroRNAs in Acute Myocardial Infarction. Front. Cardiovasc. Med., 4: 73, 2017.

17- DANESE E. and MONTAGNANA M.: An historical approach to the diagnostic biomarkers of acute coronary syndrome. Ann. Transl. Med., 4 (10): 194-204, 2016.

18- RØYSLAND R., KRAVDAL G., HØISETH A.D., et al.: Cardiac troponin $\mathrm{T}$ levels and exercise stress testing in patients with suspected coronary artery disease: The Akershus Cardiac Examination (ACE) 1 study. Clin. Sci. (Lond), 122: 599-606, 2012.

19- SABATINE M.S., MORROW D.A., De LEMOS J.A., et al.: Detection of acute changes in circulating troponin in the setting of transient stress test-induced myocardial ischaemia using an ultrasensitive assay: Results from TIMI 35. Eur. Heart. J. 30: 162-9, 2009.

20- JEREMIAS A. and GIBSON C.M.: Narrative review: Alternative causes for elevated cardiac troponin levels when acute coronary syndromes are excluded. Ann. Intern. Med., 142: 786-91, 2005.

21- MUELLER M., VAFAIE M., BIENER M., et al.: Cardiac troponin T: From diagnosis of myocardial infarction to cardiovascular risk prediction. Circ. J., 77: 1653-61, 2013.

22- CREA F., BINDER R.K. and LÜSCHER T.F.: The year in cardiology 2016: Acute coronary syndromes. European Heart Journal, 00: 1-11, 2017.

23- SHAH A.S.V., ANAND A., SANDOVAL Y., et al.: Highsensitivity cardiac troponin I at presentation in patients with suspected acute coronary syndrome: A cohort study. Lancet, 386: 2481-8, 2015.

24- PICKERING J.W., GREENSLADE J.H., CULLEN L., FLAWS D., PARSONAGE W., ALDOUS S., GEORGE P., WORSTER A., KAVSAK P.A. and THAN M.P.: Assessment of the European Society of Cardiology 0 hour/1 hour algorithm to rule out and rule in acute myocardial infarction. Circulation, 134: 1532-41, 2016.

25- COSKUNPINAR E., CAKMAK H.A., KALKAN A.K., TIRYAKIOGLU N.O. and ERTURK M.: Ongen: Circulating miR-221-3p as a novel marker for early prediction of acute myocardial infarction. Gene., 591: 90-6, 2016. 


\section{Micro RNA 208 دراسات \\ كلالالج جليدة فى أمراض الشرايين التاجية الحادة}

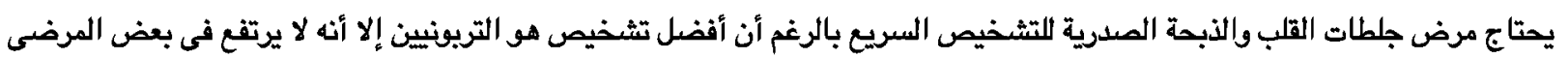

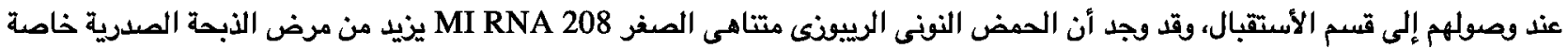
حالات قصود الشرايين الغير مستقرة.

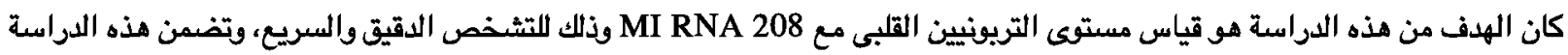
مائة مريض من قسم الأستقبال بمعهد القلب القومى أمبابة جيزة مقابل عشرين منابن مريض من الأصحاء كضوابط اللدراسة وتم تقسيمه إلى أريع مجموعات:

$$
\begin{aligned}
& \text { 1- مرض الجلطات القلية. } \\
& \text { r- برض الذبحة الصدرية الغير مستقرة. } \\
& \text { r- بـ مرض القلب بحالة أخرى. } \\
& \text { ع- مرض بغير حالات القلب ولكنه تتشابه أعراضه مثل حالات القلب. } \\
& \text { وتوصى أهمية هذه النتائج إلى الإختلاف بين دلالات القلب المطلوية. }
\end{aligned}
$$

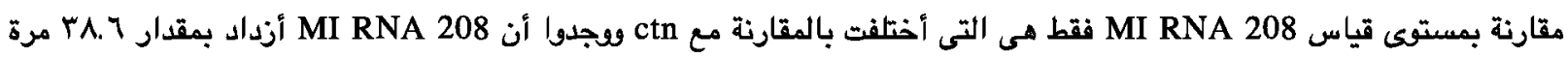

$$
\text { مستوى الضوابط. }
$$

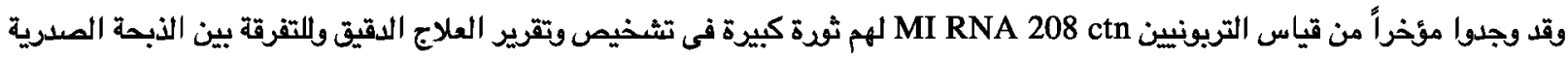

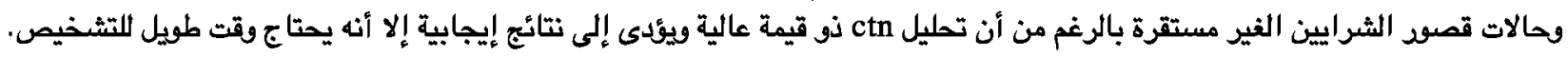

فإن قياس MI RNA 208 يستخدم كدلالة جديدة في أمراض الشرايين التاجية الحادة إلا أنه يحتاج تحليل تفاعل البلمرة التسلسلى ومازال هذا يحتاج للتطود حيث أنع يستهلك الكثير من الوقت والتكلفة أمراض المادية العالية. 